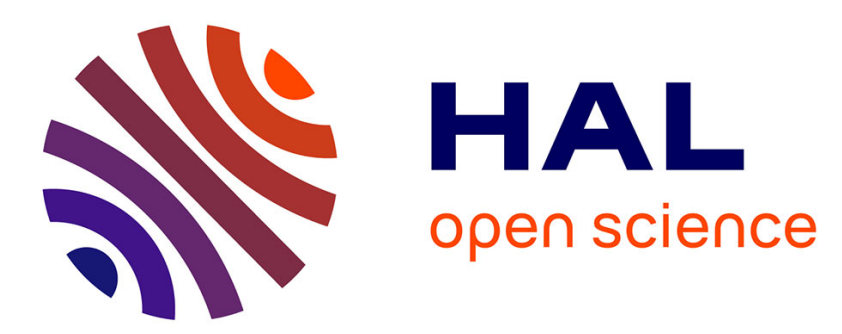

\title{
Enantioseparation of binaphthol and its monoderivatives by cyclodextrin-modified capillary zone electrophoresis: A mathematical approach
}

\author{
Nadine Mofaddel, Hour Krajian, Didier Villemin, Desbène Paul-Louis
}

\section{- To cite this version:}

Nadine Mofaddel, Hour Krajian, Didier Villemin, Desbène Paul-Louis. Enantioseparation of binaphthol and its monoderivatives by cyclodextrin-modified capillary zone electrophoresis: A mathematical approach. Talanta, 2009, 78 (2), pp.631-637. 10.1016/j.talanta.2008.12.027 . hal-02458457

\author{
HAL Id: hal-02458457 \\ https://hal.science/hal-02458457
}

Submitted on 30 Jan 2020

HAL is a multi-disciplinary open access archive for the deposit and dissemination of scientific research documents, whether they are published or not. The documents may come from teaching and research institutions in France or abroad, or from public or private research centers.
L'archive ouverte pluridisciplinaire HAL, est destinée au dépôt et à la diffusion de documents scientifiques de niveau recherche, publiés ou non, émanant des établissements d'enseignement et de recherche français ou étrangers, des laboratoires publics ou privés. 


\section{Elsevier Editorial System(tm) for Talanta Manuscript Draft}

Manuscript Number:

Title: Enantioseparation of binaphthol and its mono derivatives by CD-CZE: Mathematical approach

Article Type: Full Length Article

Keywords: binaphthol derivatives; mathematical approach; apparent complexation constant; enantioseparation; CD-CZE.

Corresponding Author: Mme Nadine Mofaddel, Ph.D.

Corresponding Author's Institution: Université de Rouen

First Author: Nadine Mofaddel, Ph.D.

Order of Authors: Nadine Mofaddel, Ph.D.; Hour Krajian, Doctorant; Didier Villemin, Professor; Paul-Louis Desbène, Professor

Abstract: A simple model for the separation of atropisomers of binaphthol and its mono derivatives by means of CD-CZE was used. This model described the migration behavior of poly charged enantiomers in a chiral separation system. Thus, this mathematical approach allowed reaching to the optimal cyclodextrin concentrations for the enantioseparation of binaphthols taking into account the influence of the formed complex mobilities. Moreover, using this theoretical approach, the reversal of enantiomers migration order as a function of cyclodextrin concentration could be predicated. At last, the apparent complexation constants between, on the one hand, the cyclodextrins and on the other hand, the binaphthol and its mono derivatives could be calculated using a non-linear curve fitting method and three linear plotting methods (x-reciprocal, y-reciprocal and double reciprocal). Good agreements between the theoretical and experimental cyclodextrin concentrations were obtained. 


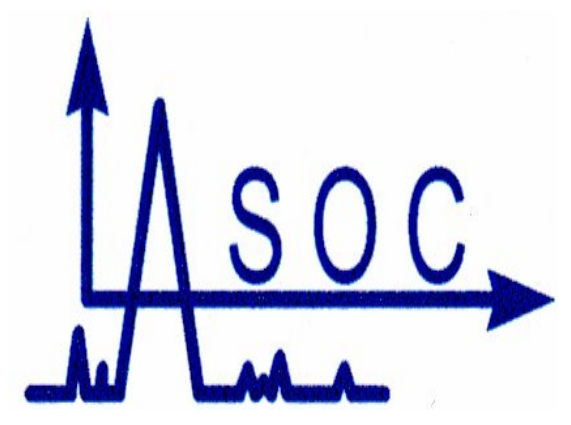

Professor Dr. Paul-Louis Desbène

Tel : (33) 0232291540

Fax (33) 0232291535

Email : paul-louis.desbene@univ-rouen.fr

\section{LABORATOIRE D'ANALYSE DES SYSTEMES} ORGANIQUES COMPLEXES

UNIVERSITE DE ROUEN

IRCOF et IFRMP

Dear Editors,

I would like to submit our work:

"Enantioseparation of binaphthol and its mono derivatives by CD-CZE: Mathematical approach"

N. Mofaddel, H. Krajian, D. Villemin and P.L. Desbène

for exclusive consideration for publication in your journal "Talanta".

This paper deals with the rationalisation of the electrophoretic behaviour of binaphthol racemates and its mono derivatives by means of capillary electrophoresis using neutral cyclodextrins. The optimal cyclodextrin concentrations deduced by this mathematical approach were compared to that obtained experimentally. Very good agreements were observed, validating in this way the apparent complexation constants for various studied binaphthol/cyclodextrin couples. Finally, the inversion in the enantiomer migration order of Binol enantiomers as a function of $\gamma$-cyclodextrin was realized using this mathematical approach.

Thank you for your consideration of our work. Feel free to correspond with me if you require further details.

Yours faithfully,

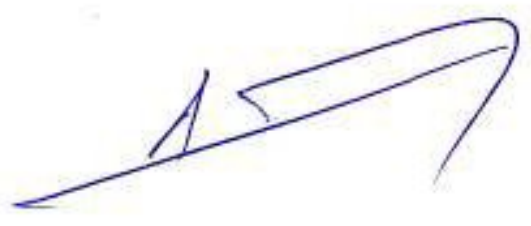

Paul-Louis Desbène 
Novelty Statement

"Enantioseparation of binaphthol and its mono derivatives by CD-CZE: Mathematical approach"

N. Mofaddel, H. Krajian, D. Villemin and P.L. Desbène

In this work, a new mathematical approach is proposed in order to rationalise the electrophoretic behaviour of binaphthol racemates and its mono derivatives by means of capillary electrophoresis using neutral cyclodextrins. 


\title{
Enantioseparation of binaphthol and its mono derivatives by CD-CZE:
}

\section{Mathematical approach}

\author{
N. Mofaddel ${ }^{1}$, H. Krajian ${ }^{1}$, D. Villemin ${ }^{2}$ and P.L. Desbène ${ }^{1 *}$ \\ ${ }^{1}$ L.A.S.O.C. - IRCOF et IFRMP, Université de Rouen, 55 rue Saint Germain, 27000 Evreux, \\ France \\ ${ }^{2}$ Laboratoire de Chimie Moléculaire - Thioorganique, UMR 6507, ENSICAEN, Université \\ de Caen, bd du Maréchal Juin, 14050 Caen, France
}

\section{Abstract}

A simple model for the separation of atropisomers of binaphthol and its mono derivatives by means of CD-CZE was used. This model described the migration behavior of poly charged enantiomers in a chiral separation system. Thus, this mathematical approach allowed reaching to the optimal cyclodextrin concentrations for the enantioseparation of binaphthols taking into account the influence of the formed complex mobilities. Moreover, using this theoretical approach, the reversal of enantiomers migration order as a function of cyclodextrin concentration could be predicated. At last, the apparent complexation constants between, on the one hand, the cyclodextrins and on the other hand, the binaphthol and its mono derivatives could be calculated using a non-linear curve fitting method and three linear plotting methods (x-reciprocal, y-reciprocal and double reciprocal). Good agreements between the theoretical and experimental cyclodextrin concentrations were obtained.

Keywords: binaphthol derivatives, mathematical approach, apparent complexation constant, enantioseparation, $C D-C Z E$

\section{Introduction}

Chiral separation by means of capillary electrophoresis (CE) has been proven an effective technique in the last recent years. Major advantages of CE consist in simplicity, high efficiency, versatility, rapid analysis, high resolution, small volume of sample and low operating costs. Enantioseparation can be achieved in CE by using chiral selectors. They are capable of discriminating between the concerned enantiomers by an enantioselective

\footnotetext{
* corresponding author : paul-louis.desbene@univ-rouen.fr
} 
complexation between the enantiomers of the analyte and the chiral selector, so that the effective electrophoretic mobility of the enantiomers can be differentiated. Numerous chiral selectors are currently available and used for enantioseparation such as cyclodextrins (CDs), chiral crown ethers, proteins, chiral surfactants, macrocyclic antibiotics, ligand-exchange complexes and polysaccharides [1]. Among them, the cyclodextrins are the most widely used chiral selectors [2].

The mechanism of the separation is fairly well understood. Several groups have developed mathematical models as theoretical approaches to evaluate the influence of the experimental variables and to describe the migration behavior of the analytes in a chiral separation system. Most models assume a 1:1 complexation between the enantiomers and the chiral selector. The analyte as well as the chiral selector may be neutral, anionic, cationic or zwitterionic. Wren and Rowe [3-6] developed the mobility difference models, while Sänger-Van de Griend et al. [7] proposed a model where one analyte has two or more complexation sites for the selector and can form multiple complexes. Vigh and coworkers introduced in a series of papers [8-10] multiple equilibrium-based mobility models including the effects of competing binding equilibriums of dissociated and non-dissociated analytes. They also developed the chiral charged resolving agent migration model (CHARM) [11]. Zhu et al. [12], Surapaneni et al. [13] and Lelièvre et al. [14] developed mathematical models for chiral separation systems using two chiral selectors.

The atropisomers of the 1,1'-binaphthyl-2,2'-diol (or Binol) became among the most widely used ligands for the asymmetric catalytic reactions, as well as a chiral host in the enantiomeric separation of racemic mixture of "guests" compounds or even as a chiral reagent during the optical purity study of the enantiomers in ${ }^{1} \mathrm{H}$ NMR. Furthermore, it was also used as enantiomeric mixture test for evaluating new or developed chiral separation systems [15]. For these reasons, the enantioseparation of Binol by $\mathrm{CE}$ has been the subject of several studies. In a previous paper [16], we studied the enantiomeric separation of Binol and its mono derivatives by means of CD-CZE. First, we determined the acidity constants of Binols. Secondly, the nature of CDs and the optimal conditions of the separation were reported. Additionally, working in a very basic medium $(\mathrm{pH}=11.5)$ was also clarified. Moreover, we observed two different types of inversion in the elution order of the two atropisomers of Binol, on the one hand, as a function of the $\mathrm{pH}$ with $\gamma$ - $\mathrm{CD}$ (pH range: 10-11.5), and on the other hand, as a function of $\gamma$-CD concentration at $\mathrm{pH}=10.8$. In this paper, we adapted a simple model in order to describe the enantioseparation of Binol and its derivatives by means of CD-CZE. The reversal of enantiomers migration order as a 
function of cyclodextrin concentration was achieved using this model. Moreover, a mathematical approach was developed in order to determine the optimal cyclodextrin concentrations. These were compared to the experimental optimal concentrations with a view to validate the theoretical model. At last, the determination of the apparent complexation constants between binaphthols and CDs were realized by four different plotting methods.

\section{Experimental}

\subsection{Instrumentation}

Capillary electrophoretic experiments were performed using a P/ACE MDQ capillary electrophoresis system (Beckman Coulter, Fullerton, CA, USA) equipped with a photodiode array detector (PDA) from 190-600 nm. An uncoated fused silica capillary (Thermo Electron $\mathrm{SA}$, Courtaboeuf, France), $40.2 \mathrm{~cm}$ long (30 $\mathrm{cm}$ to the detector), $50 \mu \mathrm{m}$ ID was used. The capillaries were thermostated at $20.0 \pm 0.1^{\circ} \mathrm{C}$. Samples were pressure-injected by $0.5 \mathrm{psi}$ (20 mbar) for $3 \mathrm{~s}$ at the inlet side of the capillary (anode). Electrophoretic runs were performed with $10 \mathrm{kV}$ potential. The UV detection was cathodic $(\lambda=214 \mathrm{~nm})$. The electropherograms were recorded and integrated by an IBM personal computer with 32 Karat software (Version 4.0, Beckman Coulter). The $\mathrm{pH}$ of the electrolyte solutions was measured using a Cyberscan pH510 pHmeter (Bioblock Scientific, Illkirch, France).

The best fit of experimental data was achieved with CurveExpert program (Version 1.38, Daniel G. Hyams, Hixson, TN, USA) for the non-linear curve fitting method and with SigmaPlot8.0 program (Version 8.02, Systat Software Inc., San Jose, USA) for the linear plotting methods.

\subsection{Chemicals and reagents}

The racemate and the $\mathrm{R}$ enantiomer of Binol (1,1'-binaphthyl-2,2'-diol or 1,1'-binaphthalen2,2'-diol) were provided by Sigma-Aldrich (Sigma-Aldrich France, Saint-Quentin-Fallavier, France). Binol derivatives studied in this work (see table 1) were synthesized by one of us as described previously [16]. Native $\alpha-C D$ was purchased from Sigma-Aldrich, $\beta$-CD (98\%) from Interchim (Interchim, Montluçon, France) and $\gamma$-CD (98\%) from Acros Organics (Acros Organics France, Noisy-le-Grand, France). 2-Hydroxypropyl- $\alpha, \beta$ and $\gamma$-CDs (HP-x-CDs) (d.s. $\approx 0.6)$ were obtained from Fluka Chemie (Sigma-Aldrich-Fluka France, L'Isle d'Abeau, 
Chesne, France) and heptakis-2,3,6-tri- $O$-methyl- $\beta$-cyclodextrin (TM- $\beta$-CD) was purchased from Sigma-Aldrich. Disodium hydrogenphosphate, trisodium phosphate and sodium hydroxide ( $+98 \%$ purity) were obtained from Sigma-Aldrich as well as absolute ethanol $(98.8 \%)$.

Table 1

\subsection{Electrolyte and sample preparation}

All running electrolytes were prepared using ultrapure water produced by a Milli-Q-System water purification apparatus (Millipore France, Montigny-le-Brotonneux, France). The solutions were sonicated just before use for 10 min by means of Branson 2510 sonication apparatus (Branson, Danbury, USA). For the enantioseparations and the apparent complexation constant determinations, a phosphate electrolyte $\left(\mathrm{Na}_{2} \mathrm{HPO}_{4}-\mathrm{Na}_{3} \mathrm{PO}_{4}\right)$ with an ionic strength equal to $80 \mathrm{mM}$ was used, the cyclodextrins concentrations ranging from $0 \mathrm{mM}$ to 20 or $25 \mathrm{mM}$. All samples were prepared in absolute ethanol at a concentration equal to $1.10^{-4} \mathrm{M}$.

In order to determine the enantiomeric migration order, the racemic sample was spiked with the R enantiomer. New uncoated capillaries were activated by performing the following washing process: water for $2 \mathrm{~min}, 1 \mathrm{M} \mathrm{NaOH}$ for $30 \mathrm{~min}$ and water for $10 \mathrm{~min}$. The capillary was conditioned for $15 \mathrm{~min}$ with the electrolyte, before running and for $2 \mathrm{~min}$ between each run.

\section{Results and discussion}

\subsection{Theory}

In our previous work [16], we reported a reversal elution order of the two atropisomers of Binol as a function of the $\mathrm{pH}$ with $\gamma-\mathrm{CD}$ ( $\mathrm{pH}$ range: 10-11.5). The $\mathrm{R}$ enantiomer of Binol migrated firstly at $\mathrm{pH}=10$ and it was secondly eluted at $\mathrm{pH}=11.5$. We proposed two hypotheses for the origin of this inversion.

The first was the progressive ionization of $\gamma-\mathrm{CD}\left(\mathrm{pK}_{\mathrm{a}}\right.$ of $\gamma-\mathrm{CD}$ is equal to 12.08) [17]. Thus at $\mathrm{pH}=10, \gamma-\mathrm{CD}$ is neutral and therefore migrates carried by the electroosmotic flow which is cathodic. Consequently, the enantiomer with the more affinity with the hydrophobic torus of $\mathrm{CD}$ migrates firstly ( $\mathrm{R}$ enantiomer of Binol), since the two enantiomers migrate towards the 
anode at this $\mathrm{pH}\left(\mathrm{pK}_{\mathrm{a} 1}\right.$ Binol $=9.04$ and $\mathrm{pK}_{\mathrm{a} 2}$ Binol $\left.=10.90\right)$. On the other hand at $\mathrm{pH}=11.5$, the $\gamma$-CD is slightly ionized (charge $<<-1 / 2$ ) and thus under such conditions it presents a slight electrophoretic mobility which is diametrically opposed to that of the electroosmotic flow and consequently it slows down enough the migration of the enantiomer which has the greatest affinity, i.e. the $\mathrm{R}$ enantiomer.

The second hypothesis was based upon the conclusions of the works of Vigh et al. [8-10]. Indeed, they modeled the enantiomeric separation of chiral weak acids and bases in CE. They showed that according to the magnitude orders of:

- the electrophoretic mobilities of dissociated analytes/CD complexes $\left(\mu_{\mathrm{RCD}}{ }^{-}\right.$and $\left.\mu_{\mathrm{SCD}}{ }^{-}\right)$, - and the complexes formation constants of the analytes dissociated and non-dissociated forms with $\mathrm{CD}$ (on the one hand $\mathrm{K}_{\mathrm{RCD}}{ }^{-}, \mathrm{K}_{\mathrm{SCD}}{ }^{-}$and on the other hand $\mathrm{K}_{\mathrm{HRCD}}, \mathrm{K}_{\mathrm{HSCD}}$ ), three kinds of separation could be envisaged as a function of the $\mathrm{pH}$ and the $\mathrm{CD}$ concentration, while the latter is systematically neutral. The three kinds are:

- desionoselective separation or Type $\mathrm{I}\left(\mu_{\mathrm{RCD}}{ }^{-}=\mu_{\mathrm{SCD}}{ }^{-} \mathrm{K}_{\mathrm{RCD}}{ }^{-}=\mathrm{K}_{\mathrm{SCD}}{ }^{-}\right.$and $\left.\mathrm{K}_{\mathrm{HRCD}} \neq \mathrm{K}_{\mathrm{HSCD}}\right)$,

- ionoselective separation or Type II $\left(\mu_{\mathrm{RCD}} \neq \mu_{\mathrm{SCD}}, \mathrm{K}_{\mathrm{RCD}}{ }^{-} \neq \mathrm{K}_{\mathrm{SCD}}{ }^{-}\right.$and $\left.\mathrm{K}_{\mathrm{HRCD}}=\mathrm{K}_{\mathrm{HSCD}}\right)$,

- duoselective separation or Type III $\left(\mu_{\mathrm{RCD}} \neq \mu_{\mathrm{SCD}}, \mathrm{K}_{\mathrm{RCD}}{ }^{-} \neq \mathrm{K}_{\mathrm{SCD}}{ }^{-}\right.$and $\left.\mathrm{K}_{\mathrm{HRCD}} \neq \mathrm{K}_{\mathrm{HSCD}}\right)$.

The two lasts allowing for, if so desired, the reversal of the migration order of the enantiomers as a function of the electrolyte composition ( $\mathrm{pH}, \mathrm{CD}$ concentration).

Therefore, the origin of the reversal migration order of Binol enantiomers as a function of the $\mathrm{pH}$ in presence of $\gamma$-CD must more probably be found in the behavior of Type II or III than in the progressive ionization of $\gamma-\mathrm{CD}$. In fact, this last remains modest even at $\mathrm{pH}=11.5$, the absolute value of its electrophoretic mobility is likely small in comparison to the electroosmotic flow.

However, the case of binaphthol and BN2 proves to be more complicated since they are diacids. Thus, all of the equilibriums reported below that are based on acid-base equilibrium must be taken into account.

$$
\begin{aligned}
& \mathrm{K}_{\mathrm{a} 1}^{\mathrm{A}} \quad \mathrm{K}_{\mathrm{a} 2}^{\mathrm{A}} \\
& \mathrm{H}_{2} \mathrm{~A} \quad \leftrightarrows \quad \mathrm{HA}^{-}+\mathrm{H}^{+} \leftrightarrows \mathrm{A}^{2-}+2 \mathrm{H}^{+} \\
& +\mathrm{C}+\mathrm{C}+\mathrm{C} \\
& \mathrm{K}_{\mathrm{AC}} \downarrow \uparrow \quad \mathrm{K}_{\mathrm{AC}^{-}} \downarrow \uparrow \quad \downarrow \uparrow \mathrm{K}_{\mathrm{AC}^{2-}} \\
& \mathrm{H}_{2} \mathrm{AC} \quad \leftrightarrows \quad \mathrm{HAC}^{-}+\mathrm{H}^{+} \leftrightarrows \mathrm{AC}^{2-}+2 \mathrm{H}^{+} \\
& \mathrm{K}_{\mathrm{a}}^{\mathrm{AC}} \quad \mathrm{K}_{\mathrm{a}}^{\mathrm{AC}^{-}}
\end{aligned}
$$


where:

$\mathrm{K}_{\mathrm{a} 1}^{\mathrm{A}}$ and $\mathrm{K}_{\mathrm{a} 2}^{\mathrm{A}}$ are the first and the second acidity constant of the diacid $\mathrm{H}_{2} \mathrm{~A}$ (or $\mathrm{A}$ );

$\mathrm{K}_{\mathrm{a}}^{\mathrm{AC}}$ and $\mathrm{K}_{\mathrm{a}}^{\mathrm{AC}^{-}}$are the acidity constants of the formed complexes $\mathrm{H}_{2} \mathrm{AC}$ and $\mathrm{HAC}^{-}$

respectively;

$\mathrm{K}_{\mathrm{AC}}, \mathrm{K}_{\mathrm{AC}}$ and $\mathrm{K}_{\mathrm{AC}^{2-}}$ are the complexation formation constants of $\mathrm{H}_{2} \mathrm{~A}$ in its non-ionized, ionized and double ionized forms respectively.

Not all data necessary to modeling the electrophoretic behavior of the enantiomers as a function of the $\mathrm{pH}$ and the cyclodextrin concentration could be accessible experimentally. Thus, we decided to simplify the model by using an apparent equilibrium and apparent constants, as it was proposed by Lelièvre and Gareil [18], in the case of the monoacids, as an alternative approach to that of Vigh et al. [8-10].

If $\mathrm{A}^{\prime}$ and $\mathrm{AC}^{\prime}$ represent the analyte and the complex respectively in their ionized and nonionized forms, then $\left[\mathrm{A}^{\prime}\right]$ is the total concentration of the analyte and its related species and $\left[\mathrm{AC}^{\prime}\right]$ is the total concentration of the complex and its related species, that is to say:

$$
\left[\mathrm{A}^{\prime}\right]=[\mathrm{A}]+\left[\mathrm{A}^{-}\right]+\left[\mathrm{A}^{2-}\right] \quad\left[\mathrm{AC}^{\prime}\right]=\left[\mathrm{H}_{2} \mathrm{AC}\right]+\left[\mathrm{HAC}^{-}\right]+\left[\mathrm{AC}^{2-}\right]
$$

Then, as in the case of monoacids [18], the whole system can be described by an apparent equilibrium and an apparent equilibrium constant $\mathrm{K}^{\prime}$ :

$$
\mathrm{A}^{\prime}+\mathrm{C} \leftrightarrows \mathrm{AC}^{\prime} \quad \mathrm{K}^{\prime}=\frac{\left[\mathrm{AC}^{\prime}\right]}{\left[\mathrm{A}^{\prime}\right][\mathrm{C}]}
$$

with:

$$
\begin{gathered}
\mathrm{K}^{\prime}=\mathrm{K}_{\mathrm{AC}} \frac{\left[\mathrm{H}^{+}\right]^{2}+\left[\mathrm{H}^{+}\right] \mathrm{K}_{\mathrm{a}}^{\mathrm{AC}}+\mathrm{K}_{\mathrm{a}}^{\mathrm{AC}} \mathrm{K}_{\mathrm{a}}^{\mathrm{AC}^{-}}}{\left[\mathrm{H}^{+}\right]^{2}+\left[\mathrm{H}^{+}\right] \mathrm{K}_{\mathrm{a} 1}^{\mathrm{A}}+\mathrm{K}_{\mathrm{a} 1}^{\mathrm{A}} \mathrm{K}_{\mathrm{a} 2}^{\mathrm{A}}}=\mathrm{K}_{\mathrm{AC}^{-}} \frac{\mathrm{K}_{\mathrm{a}}^{\mathrm{A}}}{\mathrm{K}_{\mathrm{a}}^{\mathrm{AC}}} \frac{\left[\mathrm{H}^{+}\right]^{2}+\left[\mathrm{H}^{+}\right] \mathrm{K}_{\mathrm{a}}^{\mathrm{AC}}+\mathrm{K}_{\mathrm{a}}^{\mathrm{AC}} \mathrm{K}_{\mathrm{a}}^{\mathrm{AC}}}{\left[\mathrm{H}^{+}\right]^{2}+\left[\mathrm{H}^{+}\right] \mathrm{K}_{\mathrm{a} 1}^{\mathrm{A}}+\mathrm{K}_{\mathrm{a} 1}^{\mathrm{A}} \mathrm{K}_{\mathrm{a} 2}^{\mathrm{A}}} \\
=\mathrm{K}_{\mathrm{AC}^{-}} \frac{\mathrm{K}_{\mathrm{a} 1}^{\mathrm{A}} \mathrm{K}_{\mathrm{a} 2}^{\mathrm{A}}}{\mathrm{K}_{\mathrm{a}}^{\mathrm{AC}} \mathrm{K}_{\mathrm{a}}^{\mathrm{AC}}} \frac{\left[\mathrm{H}^{+}\right]^{2}+\left[\mathrm{H}^{+}\right] \mathrm{K}_{\mathrm{a}}^{\mathrm{AC}}+\mathrm{K}_{\mathrm{a}}^{\mathrm{AC}} \mathrm{K}_{\mathrm{a}}^{\mathrm{AC}}}{\left[\mathrm{H}^{+}\right]^{2}+\left[\mathrm{H}^{+}\right] \mathrm{K}_{\mathrm{a} 1}^{\mathrm{A}}+\mathrm{K}_{\mathrm{a} 1}^{\mathrm{A}} \mathrm{K}_{\mathrm{a} 2}^{\mathrm{A}}}
\end{gathered}
$$

If all equilibriums are fast, then $\mu_{\mathrm{A}}$, the mobility of $\mathrm{H}_{2} \mathrm{~A}$ (or $\mathrm{A}$ ), is a linear combination of its mobility in free solution $\left(\mu_{\mathrm{A}}\right)$ and its mobility when it is totally complexed $\left(\mu_{\mathrm{C}}\right)$ :

with:

$$
\mu_{\mathrm{A}}=\frac{\left[\mathrm{A}^{\prime}\right]}{\left[\mathrm{A}^{\prime}\right]+\left[\mathrm{AC}^{\prime}\right]} \mu_{\mathrm{f}}+\frac{\left[\mathrm{A}^{\prime}\right]}{\left[\mathrm{A}^{\prime}\right]+\left[\mathrm{AC}^{\prime}\right]} \mu_{\mathrm{C}}
$$

$$
\mu_{\mathrm{f}}=\frac{\left[\mathrm{H}^{+}\right]^{2}}{\left[\mathrm{H}^{+}\right]^{2}+\left[\mathrm{H}^{+}\right] \mathrm{K}_{\mathrm{a} 1}^{\mathrm{A}}+\mathrm{K}_{\mathrm{a} 1}^{\mathrm{A}} \mathrm{K}_{\mathrm{a} 2}^{\mathrm{A}}} \mu_{\mathrm{A}}+\frac{\left[\mathrm{H}^{+}\right] \mathrm{K}_{\mathrm{a} 1}^{\mathrm{A}}}{\left[\mathrm{H}^{+}\right]^{2}+\left[\mathrm{H}^{+}\right] \mathrm{K}_{\mathrm{a} 1}^{\mathrm{A}}+\mathrm{K}_{\mathrm{a} 1}^{\mathrm{A}} \mathrm{K}_{\mathrm{a} 2}^{\mathrm{A}}} \mu_{\mathrm{A}^{-}}+\frac{\mathrm{K}_{\mathrm{a} 1}^{\mathrm{A}} \mathrm{K}_{\mathrm{a} 2}^{\mathrm{A}}}{\left[\mathrm{H}^{+}\right]^{2}+\left[\mathrm{H}^{+}\right] \mathrm{K}_{\mathrm{a} 1}^{\mathrm{A}}+\mathrm{K}_{\mathrm{a} 1}^{\mathrm{A}} \mathrm{K}_{\mathrm{a} 2}^{\mathrm{A}}} \mu_{\mathrm{A}^{2-}}
$$


$\mu_{\mathrm{C}}=\frac{\left[\mathrm{H}^{+}\right]^{2}}{\left[\mathrm{H}^{+}\right]^{2}+\left[\mathrm{H}^{+}\right] \mathrm{K}_{\mathrm{a}}^{\mathrm{AC}}+\mathrm{K}_{\mathrm{a}}^{\mathrm{AC}} \mathrm{K}_{\mathrm{a}}^{\mathrm{AC}}} \mu_{\mathrm{AC}}+\frac{\left[\mathrm{H}^{+}\right] \mathrm{K}_{\mathrm{aC}}^{\mathrm{AC}}}{\left[\mathrm{H}^{+}\right]^{2}+\left[\mathrm{H}^{+}\right] \mathrm{K}_{\mathrm{a}}^{\mathrm{AC}}+\mathrm{K}_{\mathrm{a}}^{\mathrm{AC}} \mathrm{K}_{\mathrm{a}}^{\mathrm{AC}}} \mu_{\mathrm{AC}}+\frac{\mathrm{K}_{\mathrm{a}}^{\mathrm{AC}} \mathrm{K}_{\mathrm{a}}^{\mathrm{AC}}}{\left[\mathrm{H}^{+}\right]^{2}+\left[\mathrm{H}^{+}\right] \mathrm{K}_{\mathrm{a}}^{\mathrm{AC}}+\mathrm{K}_{\mathrm{a}}^{\mathrm{AC}} \mathrm{K}_{\mathrm{a}}^{\mathrm{AC}}} \mu_{\mathrm{AC}^{2-}}$ where: $\mu_{\mathrm{A}^{-}}, \mu_{\mathrm{A}^{2-}}, \mu_{\mathrm{AC}}, \mu_{\mathrm{AC}^{-}}$and $\mu_{\mathrm{AC}^{2-}}$ are the absolute mobility of $\mathrm{HA}^{-}, \mathrm{A}^{2-}, \mathrm{H}_{2} \mathrm{AC}, \mathrm{HAC}^{-}$and $\mathrm{AC}^{2-}$ respectively.

Let us note that the first term in the equation that defines $\mu_{\mathrm{f}}$ is systematically null, the acid compounds present a null electrophoretic mobility in ion suppression.

Then, the mobility of $\mathrm{H}_{2} \mathrm{~A}$ (or A) can be expressed as a function of the apparent equilibrium constant and the ligand concentration, which is the same equation in the case of monoacid but with different constant:

$\mu_{\mathrm{A}}=\frac{1}{1+\mathrm{K}^{\prime}[\mathrm{C}]} \mu_{\mathrm{f}}+\frac{\mathrm{K}^{\prime}[\mathrm{C}]}{1+\mathrm{K}^{\prime}[\mathrm{C}]} \mu_{\mathrm{C}}$

If $\mathrm{A}$ is a racemic mixture then the mobility of each enantiomer ( $\mathrm{S}$ or $\mathrm{R}$ ) can be described using (eq.5):

$$
\mu_{\mathrm{S}}=\frac{\mu_{\mathrm{f}}+\mu_{\mathrm{SC}} \mathrm{K}_{\mathrm{S}}^{\prime}[\mathrm{C}]}{1+\mathrm{K}_{\mathrm{S}}^{\prime}[\mathrm{C}]} \mu_{\mathrm{R}}=\frac{\mu_{\mathrm{f}}+\mu_{\mathrm{RC}} \mathrm{K}_{\mathrm{R}}^{\prime}[\mathrm{C}]}{1+\mathrm{K}_{\mathrm{R}}^{\prime}[\mathrm{C}]}
$$

where:

$\mu_{\mathrm{S}}$ and $\mu_{\mathrm{R}}$ are the mobility of $\mathrm{S}$ and $\mathrm{R}$ enantiomers respectively;

$\mu_{\mathrm{f}}$ is the mobility of the free enantiomer;

$\mu_{\mathrm{SC}}$ and $\mu_{\mathrm{RC}}$ are the mobilities of the complexed $\mathrm{S}$ and $\mathrm{R}$ enantiomers respectively;

$\mathrm{K}_{\mathrm{S}}^{\prime}$ and $\mathrm{K}_{\mathrm{R}}^{\prime}$ are the apparent complexation constants between $\mathrm{S}$ and $\mathrm{R}$ enantiomers

respectively and the ligand;

and finally, $[\mathrm{C}]$ is the ligand concentration.

As a result, similar equations are obtained for both monoacid and diacid with different apparent complexation constants. Moreover, the mobilities of the complexed S and R enantiomers are slightly different from each other due to the difference in their acidity constants as it could be observed from (eq.4).

For determination of the apparent complexation constant, (eqs.6) can be used. Additionally, linear plotting (eqs.7-9) can be obtained from these equations and they have been used in CE for determination of binding constant. It should be noticed that these linear plotting equations are analogous to those that have been employed for spectroscopy, chromatography and calorimetry techniques. These three linear plotting equations are known as double reciprocal 
(eq.7) with $\mathrm{K}^{\prime}=$ intercept / slope, y-reciprocal (eq.8) with $\mathrm{K}^{\prime}=$ slope / intercept and finally x-reciprocal (eq.9) with $\mathrm{K}^{\prime}=$ - slope.

$$
\begin{aligned}
& \frac{1}{\left(\mu_{\mathrm{i}}-\mu_{\mathrm{f}}\right)}=\frac{1}{\left(\mu_{\mathrm{C}}-\mu_{\mathrm{f}}\right) \mathrm{K}^{\prime}} \frac{1}{[\mathrm{C}]}+\frac{1}{\left(\mu_{\mathrm{C}}-\mu_{\mathrm{f}}\right)} \\
& \frac{[\mathrm{C}]}{\left(\mu_{\mathrm{i}}-\mu_{\mathrm{f}}\right)}=\frac{1}{\left(\mu_{\mathrm{C}}-\mu_{\mathrm{f}}\right)}[\mathrm{C}]+\frac{1}{\left(\mu_{\mathrm{C}}-\mu_{\mathrm{f}}\right) \mathrm{K}^{\prime}} \\
& \frac{\left(\mu_{\mathrm{i}}-\mu_{\mathrm{f}}\right)}{[\mathrm{C}]}=-\mathrm{K}^{\prime}\left(\mu_{\mathrm{i}}-\mu_{\mathrm{f}}\right)+\mathrm{K}^{\prime}\left(\mu_{\mathrm{C}}-\mu_{\mathrm{f}}\right)
\end{aligned}
$$

Armstrong et al. [19] compared these different equations for estimation of binding constant by CE for both achiral and chiral analytes. Bellini et al. [20] determined the apparent association constants of four model drugs with $\beta$-CD by $\mathrm{CE}$ and compared the results obtained by these three linear plotting methods. The great advantage of non-linear curve fitting method (eqs.6) is the determination of $\mu_{\mathrm{f}}$ and $\mu_{\mathrm{C}}$ by fitting the experimental data to the equations. Then, we can compare between $\mu_{\mathrm{f}}$ and its value determined experimentally where no chiral selector is present. Moreover, we do not need to measure $\mu_{C}$ experimentally in order to determine the binding constant. $\mu_{\mathrm{C}}$ often cannot be accurately measured or even it is impossible to be determined due to experimental limitations such as ligand solubility [21] or the capillary wall binding by the ligand [22]. The non-linear curve fitting methods avoid these problems and disadvantages. Similarly, the linear methods (eqs.7-9) are also advantageous for the systems where the mobility of the analyte-ligand complex is not known and cannot be adequately measured with a marker or at saturating concentrations of the ligand.

These four plotting methods were used to estimate the apparent complexation constants of binaphthols and cyclodextrins at $\mathrm{pH}=11.5$, where the advantage of working at this $\mathrm{pH}$ for enantioseparation of Binols was previously reported [16].

The mobilities of the analytes were systematically corrected for the electrolytes viscosity changes due to the augmentation of CDs concentration. Thus, the electrophoretic mobilities were multiplied by the ratio between the currents obtained without and with CD in the solution [23].

The $\mathrm{pK}_{\mathrm{a}}$ of cyclodextrins is about (12.08-12.3) [24], thus the cyclodextrin can begin to be dissociated at $\mathrm{pH}=11.5$ and could exist in ionized form. However, the ionization percentage is almost poor $\approx 15 \%$ and as a first approximation we will hypothesize that the latter does not influence the determination of apparent complexation constant and complex mobility. This hypothesis is validated by the comparison between the calculated mobility of free Binol in the 
case of the various studied CD using (eqs.6) and the experimental value measured without CD (see table 2). In fact, a good agreement is observed between the experimental and calculated values and therefore, at $\mathrm{pH}=11.5$ the dissociation of $\mathrm{CD}$ can be effectively considered as negligible and it could not influence the calculation.

\section{Table 2}

As a result, the proposed model could be used for estimating the apparent complexation constants between binaphthols and cyclodextrins at $\mathrm{pH}=11.5$.

\subsection{Apparent complexation constants and complex mobilities}

As it was illustrated above by the mathematical approach, in the case of binaphthol, the mobilities of the $\mathrm{S}$ and $\mathrm{R}$ complexed enantiomers are different from each other. The figure 1a reports the theoretical evolution of the electrophoretic mobilities as a function $\gamma-C D$ concentration for the $\mathrm{R}$ and $\mathrm{S}$ enantiomers of Binol. While the table 3 contains the apparent complexation constants between these two enantiomers and $\gamma$-CD as well as the complex mobilities, as they were deduced from the theoretical approach and the correlation coefficients.

Table 3

It should be noted that these correlation coefficients are good. By examination of the table 3 we find that, in the present case, not only the apparent complexation constants between the two enantiomers and $\gamma$-CD are different $\left(235 \mathrm{M}^{-1}\right.$ for the $\mathrm{S}$ enantiomer against only $194 \mathrm{M}^{-1}$ in the case of the R enantiomer), but also the electrophoretic mobilities of the formed complexes are slightly different. In addition, the absolute values of the electrophoretic mobilities of SBinol $/ \gamma-C D$ complex are higher than that of R-Binol $/ \gamma-C D$ complex. In fact, the electrophoretic mobilities of these two complexes, as they are deduced from the theoretical treatment, are equal to $-0.49 \times 10^{-8}$ and $-0.43 \times 10^{-8} \mathrm{~m}^{2} \cdot \mathrm{V}^{-1} \cdot \mathrm{s}^{-1}$ respectively. This difference in the apparent complexation constants for the Binol enantiomers as well as the difference in the mobilities of Binol $/ \gamma-C D$ complexes $\left(K_{S}^{\prime}>K_{R}^{\prime}\right.$ and $\left.\mu_{S C}>\mu_{R C}\right)$ rationalize the inversion observed experimentally, as it is shown in the figure $1 \mathrm{~b}$. 
Figure 1

The apparent complexation constants calculated between the two Binol enantiomers and $\gamma$-CD $\left(K_{S}^{\prime}=235 \mathrm{M}^{-1}\right.$ and $\left.K_{R}^{\prime}=194 \mathrm{M}^{-1}\right)$ are nearer from that given by Zerbinati and Trotta [25], for the same enantiomers and the same cyclodextrin, $\left(272 \mathrm{M}^{-1}\right.$ for the $\mathrm{S}$ enantiomer and $246 \mathrm{M}^{-1}$ for the $\mathrm{R}$ enantiomer). In fact, the constants that we deduced have the same magnitude to that reported by these authors and the interactions of the $\mathrm{S}$ enantiomer with the hydrophobic torus of $\gamma$-CD are more favorable in the two cases. On the other hand the $K_{S}^{\prime} / K_{R}^{\prime}$ ratio and thus the thermodynamic selectivity proves to be higher in our case than in the study of Zerbinati and Trotta, that is, 1.22 against 1.11 . However, the approach used by these authors is critical since they deduced their different values by applying the model of Wren and Rowe [3-6], that means without taking into account the incomplete dissociation of binaphthol.

The table 4 shows some examples of the complex mobility of various binaphthol (S,R) / CD couples calculated using (eqs.6) and for which no inversion in the enantiomer migration order was observed as a function of cyclodextrin concentration.

Table 4

Such an observation could be attributed to insufficient difference of the electrophoretic mobilities of the $\mathrm{S}$ and $\mathrm{R}$ formed complexes together with the magnitudes of the apparent complexation constants between the two enantiomers and the CD. In fact, the reported values of $\Delta \mu_{\mathrm{C}}$ in the table 4 are at most equal to $0.04 \times 10^{-8} \mathrm{~m}^{2} . \mathrm{V}^{-1} \cdot \mathrm{s}^{-1}$, which probably must be nearer to calculated $\Delta \mu_{\mathrm{C}}$ value in the case of Binol and $\gamma-\mathrm{CD}\left(0.06 \times 10^{-8} \mathrm{~m}^{2} \cdot \mathrm{V}^{-1} \cdot \mathrm{s}^{-1}\right)$. These remains insufficient in order to such an inversion could be observed in the range of experimentally explored concentration.

The table 5 shows the apparent complexation constant calculated, for the various studied binaphthol/CD couples, by means of the four plotting methods (x-reciprocal, y-reciprocal, double reciprocal and non-linear).

Table 5 
A good linearization with all the three plotting methods was observed with average correlation coefficients of 0.997 . Good correlation coefficients were also observed for the non-linear method (average of 0.9991 ). As a result, a satisfactory agreement between the four methods is observed, whatever is the considered $\mathrm{BN} / \mathrm{CD}$ couple.

For comparing the affinity between the different cyclodextrins and the binaphthols, we can notice that, with regard to the studied CDs, HP- $\beta-C D$ has the preferable great affinity with the binaphthols, while $\alpha-C D$ has the lowest one. Moreover, we find that the derivative CDs have relatively more strong affinity with the binaphthols contrary to the corresponding native ones, except with $\gamma-C D$, which proves to develop globally more strong interactions than its homologue HP- $\gamma$-CD derivative.

Finally, in the case of the Binol with the $\gamma-\mathrm{CD}$, the effect of increasing the electrolyte $\mathrm{pH}$ by 0.7 units leads to decreasing the affinity of the two enantiomers for the hydrophobic cavity of the cyclodextrin, as we could expect it since the ionization degree is reinforced for the two partners.

\subsection{Determination of $\left(\Delta \mu_{S, R \text { max }}\right)$ and optimal concentration of cyclodextrin}

The mobility difference between a pair of $\mathrm{S}$ and R enantiomers $\left(\Delta \mu_{\mathrm{S}, \mathrm{R}}\right)$ can be described from (eqs.6), as in its most general form:

$$
\Delta \mu_{\mathrm{S}, \mathrm{R}}=\frac{\mu_{\mathrm{f}}+\mu_{\mathrm{RC}} \mathrm{K}_{\mathrm{R}}^{\prime}[\mathrm{C}]}{1+\mathrm{K}_{\mathrm{R}}^{\prime}[\mathrm{C}]}-\frac{\mu_{\mathrm{f}}+\mu_{\mathrm{SC}} \mathrm{K}_{\mathrm{S}}^{\prime}[\mathrm{C}]}{1+\mathrm{K}_{\mathrm{S}}^{\prime}[\mathrm{C}]}
$$

then, $\left(\Delta \mu_{\mathrm{S}, \mathrm{R}}\right)$ depends not only on the apparent complexation constants of both $\mathrm{S}, \mathrm{R}$ enantiomers with the chiral selector but also on the electrophoretic mobility of each complex formed between the S, R enantiomers with the chiral selector and finally on the concentration of the chiral selector. Therefore, the optimal chiral selector concentration, which leads to a maximum electrophoretic mobility $\left(\Delta \mu_{\mathrm{S}, \mathrm{R} \max }\right)$ difference, can be achieved when $\frac{\partial \Delta \mu_{\mathrm{S}, \mathrm{R}}}{\partial \mathrm{C}}=0$ (11). Wren and Rowe simplified, in their model $[3,4]$, the determination of $\left[\mathrm{C}_{\mathrm{opt}}\right]$ assuming that $\mu_{\mathrm{SC}}=\mu_{\mathrm{RC}}=\mu_{\mathrm{C}}$ and then $\left[\mathrm{C}_{\mathrm{opt}}\right]=\frac{1}{\sqrt{\mathrm{K}_{\mathrm{S}} \mathrm{K}_{\mathrm{R}}}}$. While in the case of the Binols and as it was illustrated above $\mu_{\mathrm{SC}} \neq \mu_{\mathrm{RC}}$, and Wren-Rowe's model is not valid, therefore a direct resolution of (eq.11) must be used. The latter leads to a classic polynomial equation in form of:

$$
\mathrm{a}[\mathrm{C}]^{2}+\mathrm{b}[\mathrm{C}]+\mathrm{c} \text { with }[\mathrm{Copt}]=\frac{-\mathrm{b}+\sqrt{\Delta}}{2 \mathrm{a}}
$$


where: $\Delta=b^{2}-4 a c, a=K_{S}^{\prime} K_{R}^{\prime}\left[K_{S}^{\prime}\left(\mu_{R C}-\mu_{f}\right)-K_{R}^{\prime}\left(\mu_{S C}-\mu_{f}\right), b=2 K_{S}^{\prime} K_{R}^{\prime}\left(\mu_{R C}-\mu_{S C}\right)\right.$ and $\mathrm{c}=\mathrm{K}_{\mathrm{R}}^{\prime}\left(\mu_{\mathrm{RC}}-\mu_{\mathrm{f}}\right)-\mathrm{K}_{\mathrm{S}}^{\prime}\left(\mu_{\mathrm{SC}}-\mu_{\mathrm{f}}\right)$.

The table 6 shows the comparison between the theoretical optimal concentration of the cyclodextrin $\left[\mathrm{C}_{\mathrm{opt}}\right]_{\mathrm{cal}}$ calculated by using (eq.12) and the experimental optimal concentration of the cyclodextrin $\left[\mathrm{C}_{\mathrm{opt}}\right]_{\exp }$ determined experimentally by $\left(\Delta \mu_{\mathrm{S}, \mathrm{R} \exp }\right)$ plotting as a function of cyclodextrin concentration (0-20 or $25 \mathrm{mM})$.

Table 6

We found a good agreement between the two concentrations. Moreover, by elimination the value of $\left[\mathrm{C}_{\mathrm{opt}}\right]_{\mathrm{cal}}$ corresponding to Bin 1 and $\alpha-\mathrm{CD}$ which is outside of the studied concentration rang then we obtain $94 \%$ correlation between $\left[\mathrm{C}_{\mathrm{opt}}\right]_{\mathrm{cal}}$ and $\left[\mathrm{C}_{\mathrm{opt}}\right]_{\mathrm{exp}}$. As a result, the proposed model is perfectly adapted to describe the electrophoretic behavior for the enantioseparation of binaphthols by CD-CZE and the formed hypothesis, namely the weak electrophoretic mobilities of the various studied cyclodextrins could be negligible.

\section{Conclusion}

With regard to these results, we can conclude that the proposed theoretical model is quite adapted to describe the electrophoretic behavior of the binaphthols in CD-CZE under the studied conditions ( $\mathrm{pH}$ range from 10.8 to 11.5 ) and consequently to modeling the enantioseparation of binaphthols by means of CD-CZE.

The optimal cyclodextrin concentrations for the enantioseparation of binaphthols determined by this model are in strong agreement with the values deduced from the experimentations. Moreover, the electrophoretic mobilities of the complexes formed between the binaphthols and the various studied cyclodextrins play a significant role in the enantioseparation. This model can be applied to:

- determine the optimal concentration of the chiral selector for the weak monoacid and diacid analytes,

- the reversal of the enantiomer migration order as a function of the chiral selector concentration, using the apparent complexation constants and the complex mobilities.

\section{References}


[1] G. Gübitz, M.G. Schmid, J. Chromatogr. A, 792 (1997) 179.

[2] S. Fanali, J. Chromatogr. A, 875 (2000) 89.

[3] S.A.C. Wren, R.C. Rowe, J. Chromatogr., 603 (1992) 235.

[4] S.A.C. Wren, R.C. Rowe, J. Chromatogr., 635 (1993) 113.

[5] S.A.C. Wren, J. Chromatogr., 636 (1993) 57.

[6] S.A.C. Wren, Electrophoresis, 16 (1995) 2127.

[7] C.E. Sänger-Van de Griend, K. Gröningsson, T. Arvidsson, J. Chromatogr. A, 782 (1997) 271.

[8] Y.Y. Rawjee, D.U. Staerk, G. Vigh, J. Chromatogr., 635 (1993) 291.

[9] Y.Y. Rawjee, R.L. Williams, G. Vigh, J. Chromatogr. A, 652 (1993) 233.

[10] Y.Y. Rawjee, R.L. Williams, G. Vigh, J. Chromatogr. A, 680 (1994) 599.

[11] B.A. Williams, G. Vigh, J. Chromatogr. A, 777 (1997) 295.

[12] X. Zhu, Y. Ding, B. Lin, A. Jakob, B. Koppenhoefer, J. Chromatogr. A, 888 (2000) 241.

[13] S. Surapaneni, K. Ruterbories, T. Lindstrom, J. Chromatogr. A, 761 (1997) 249.

[14] F. Lelievre, P. Gareil, Y. Bahaddi, H. Galons, Anal. Chem., 69 (1997) 393.

[15] J.M. Brunel, Chem. Rev., 105 (2005) 857.

[16] N. Mofaddel, H. Krajian, D. Villemin, P.L. Desbène submitted to J. Chromatogr. A.

[17] S. Li, W.C. Purdy, Chem. Rev., 92 (1992) 1457.

[18] F. Lelièvre, P. Gareil, Anal. Chem., 69 (1997) 385.

[19] K.L. Rundlett, D.W. Armstrong, J. Chromatogr. A, 721 (1996) 173.

[20] M.S. Bellini, Z. Deyl, G. Manetto, M. Kohlíčková, J. Chromatogr. A, 924 (2001) 483.

[21] A. Shibukawa, D.K. Lloyd, I.W. Wainer, Chromatographia, 35 (1993) 419.

[22] K.L. Rundlett, D.W. Armstrong, Anal. Chem., 67 (1995) 2088.

[23] R. Vespalec, P. Boček, J. Chromatogr. A, 875 (2000) 431.

[24] B. Chankvetadze, Capillary Electrophoresis in Chiral Analysis, Wiley, Chichester, 1997, Ch.12, p. 428.

[25] O. Zerbinati, F. Trotta, Electrophoresis, 22 (2001) 3578. 
Figure 1: a) Variations of the electrophoretic mobility of Binol enantiomers as a function of $\gamma$-CD concentration.

Curves identification: $\Delta$ experimental points and continuous line for R-Binol

o experimental points and dashed line for S-Binol

b) Enantioseparation of Binol enantiomers with different concentrations of $\gamma$-CD.

Experimental conditions: uncoated silica capillary $(30$ (40.2) $\mathrm{cm} \times 50 \mu \mathrm{m} I D)$; hydrodynamic injection: $3 \mathrm{~s}$ at $0.5 \mathrm{psi} ; \mathrm{T}=20^{\circ} \mathrm{C} ; \lambda=214 \mathrm{~nm}$; voltage: $10 \mathrm{kV}$; electrolyte: $\mathrm{Na}_{2} \mathrm{HPO}_{4} / \mathrm{Na}_{3} \mathrm{PO}_{4}$; $p H=10.8$; ionic strength: $8.10^{-2} \mathrm{M} ;[\gamma-C D]$ : variable; sample: Binol racemate spiked with the $R$ enantiomer.









Table 1: Structures of the studied Binol and its derivatives.

\begin{tabular}{|c|c|c|}
\hline Name & Abbreviation & Structure \\
\hline 1,1'-binaphthalen-2,2'-diol & Binol & \\
\hline $\begin{array}{l}\text { 6-bromo-1-(2-hydroxynaphthalen-1- } \\
\text { yl)naphthalen-2-ol }\end{array}$ & $\mathrm{BN} 2$ & \\
\hline 1-(2-(allyloxy)naphthalen-1-yl)naphthalen-2-ol & $\mathrm{BN} 3$ & \\
\hline 1-(2-(benzyloxy)naphthalen-1-yl)naphthalen-2-ol & $\mathrm{BN} 4$ & \\
\hline 1-(2-methoxynaphthalen-1-yl)naphthalen-2-ol & BN5 & \\
\hline
\end{tabular}


Table 2: Comparison between the experimental and calculated values of free Binol mobility in the case of various experimentations realized during the enantioseparation of Binol by means of various cyclodextrins at $\mathrm{pH}=11.5$.

\begin{tabular}{|c|c|c|c|}
\hline & $\begin{array}{c}\boldsymbol{\mu}_{\text {free, } \exp } \\
\left(10^{-8} m^{2} \cdot V^{1} \cdot s^{-1}\right)\end{array}$ & Binol $(\mathbf{S}, \mathbf{R})$ & $\begin{array}{c}\boldsymbol{\mu}_{\text {free, }} \text { cal } \\
\left(10^{-8} m^{2} \cdot V^{-1} \cdot s^{-1}\right)\end{array}$ \\
\hline \multirow{2}{*}{$\alpha-C D$} & \multirow{2}{*}{-2.00} & $\mathrm{~S}$ & -2.00 \\
\hline & & $\mathrm{R}$ & -2.01 \\
\hline \multirow{2}{*}{$\beta-C D$} & \multirow{2}{*}{-2.00} & S & -2.02 \\
\hline & & $\mathrm{R}$ & -2.02 \\
\hline \multirow{2}{*}{$\gamma-C D$} & \multirow{2}{*}{-2.01} & $S$ & -2.01 \\
\hline & & $\mathrm{R}$ & -2.02 \\
\hline \multirow{2}{*}{$H P-\alpha-C D$} & \multirow{2}{*}{-2.03} & $\mathrm{~S}$ & -2.02 \\
\hline & & $\mathrm{R}$ & -2.02 \\
\hline \multirow{2}{*}{ HP- $\beta-C D$} & \multirow{2}{*}{-2.09} & $\mathrm{~S}$ & -2.10 \\
\hline & & $\mathrm{R}$ & -2.11 \\
\hline \multirow{2}{*}{ HP- $\gamma-C D$} & \multirow{2}{*}{-2.13} & $\mathrm{~S}$ & -2.12 \\
\hline & & $\mathrm{R}$ & -2.13 \\
\hline \multirow{2}{*}{ TM- $\beta-C D$} & \multirow{2}{*}{-2.12} & $\mathrm{~S}$ & -2.13 \\
\hline & & $\mathrm{R}$ & -2.13 \\
\hline
\end{tabular}

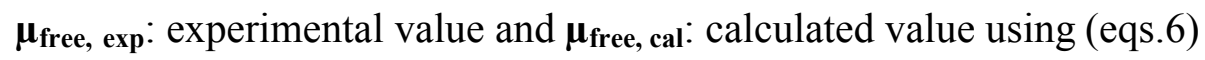


Table 3: The apparent complexation constants, and the complex mobilities $\mu_{\mathrm{SC}}, \mu_{\mathrm{RC}}$ between the $\mathrm{S}, \mathrm{R}$ enantiomers of Binol and $\gamma-\mathrm{CD}$ at $\mathrm{pH}=10.8$.

\begin{tabular}{|c|c|c|}
\hline $\mathrm{K}_{\mathrm{S}}^{\prime}\left(\mathrm{M}^{-1}\right)$ & $\mu_{\mathrm{SC}}\left(10^{-8} \mathrm{~m}^{2} \cdot \mathrm{V}^{-1} \cdot \mathrm{s}^{-1}\right)$ & $\mathrm{R}^{2}$ \\
\hline 235 & -0.49 & 0.9996 \\
\hline $\mathrm{K}_{\mathrm{R}}^{\prime}\left(\mathrm{M}^{-1}\right)$ & $\mu_{\mathrm{RC}}\left(10^{-8} \mathrm{~m}^{2} \cdot \mathrm{V}^{-1} \cdot \mathrm{s}^{-1}\right)$ & $\mathrm{R}^{2}$ \\
\hline 194 & -0.43 & 0.9996 \\
\hline
\end{tabular}


Table 4: Calculated mobilities of the formed complexes in the case of various BN/CD couples at $\mathrm{pH}=11.5$ using eqs.6.

\begin{tabular}{|c|c|c|}
\hline Binols & CD & $\begin{array}{c}\boldsymbol{\mu}_{\mathbf{c}, \mathbf{c a l}} \\
\left(10^{-8} \mathrm{~m}^{2} \cdot V^{-1} \cdot s^{-1}\right)\end{array}$ \\
\hline Binol (S) & \multirow{2}{*}{$\alpha-C D$} & -0.37 \\
\hline Binol (R) & & -0.39 \\
\hline BN2 (1) & \multirow{2}{*}{ HP- $\gamma-\mathrm{CD}$} & -0.45 \\
\hline BN2 (2) & & -0.44 \\
\hline BN3 (1) & \multirow{2}{*}{$\gamma-\mathrm{CD}$} & -0.38 \\
\hline BN3 (2) & & -0.34 \\
\hline BN4 (1) & \multirow{2}{*}{$H P-\alpha-C D$} & -0.46 \\
\hline BN4 (2) & & -0.43 \\
\hline BN5 (1) & \multirow{2}{*}{$\beta-C D$} & -0.34 \\
\hline BN5 (2) & & -0.32 \\
\hline
\end{tabular}

(1) and (2) corresponding to the first and second peaks of $B N$ racemates 
Table 5: Apparent complexation constants of different binaphthols and cyclodextrins calculated at $\mathrm{pH}=11.5$ by the four plotting methods $(\mathbf{X})$ : $\mathrm{x}$-reciprocal, $(\mathbf{Y})$ : y-reciprocal, (XY): double reciprocal and (XYZ): non-linear. $\left(\mathrm{K}^{\prime}\right.$ in $\left.\mathrm{M}^{-1}\right)$

\begin{tabular}{|c|c|c|c|c|c|c|c|c|c|c|}
\hline & \multicolumn{2}{|c|}{ Binol } & \multirow{2}{*}{\multicolumn{2}{|c|}{$\begin{array}{l}\text { BN2 } \\
\text { S/R }\end{array}$}} & \multirow{2}{*}{\multicolumn{2}{|c|}{$\begin{array}{l}\text { BN3 } \\
\text { S/R }\end{array}$}} & \multicolumn{2}{|c|}{ BN4 } & \multicolumn{2}{|c|}{ BN5 } \\
\hline$\alpha-C D$ & $\mathbf{S}$ & $\mathbf{R}$ & & & & & 1 & 2 & 1 & 2 \\
\hline$K^{\prime}(X)$ & 27 & 18 & \multicolumn{2}{|c|}{33} & \multicolumn{2}{|c|}{34} & 32 & 23 & 22 & 15 \\
\hline $\mathbf{K}^{\prime}(\mathbf{Y})$ & 27 & 20 & \multicolumn{2}{|c|}{33} & \multicolumn{2}{|c|}{34} & 31 & 23 & 22 & 15 \\
\hline $\mathbf{K}^{\prime}(\mathrm{XY})$ & 29 & 20 & \multicolumn{2}{|c|}{30} & \multicolumn{2}{|c|}{34} & 34 & 25 & 22 & 15 \\
\hline $\mathbf{K}^{\prime}(\mathrm{XYZ})$ & 25 & 23 & \multicolumn{2}{|c|}{32} & \multicolumn{2}{|c|}{25} & 23 & 15 & 22 & 20 \\
\hline$\beta-C D$ & $\mathbf{S}$ & $\mathbf{R}$ & 1 & 2 & 1 & 2 & 1 & 2 & 1 & 2 \\
\hline$K^{\prime}(X)$ & 125 & 83 & 454 & 289 & 116 & 41 & 154 & 105 & 95 & 32 \\
\hline$K^{\prime}(Y)$ & 129 & 85 & 447 & 299 & 114 & 41 & 155 & 106 & 92 & 33 \\
\hline $\mathbf{K}^{\prime}(\mathrm{XY})$ & 113 & 73 & 445 & 274 & 123 & 39 & 158 & 105 & 106 & 32 \\
\hline \multirow[t]{2}{*}{$\mathbf{K}^{\prime}(\mathrm{XYZ})$} & 150 & 106 & \multirow{2}{*}{\multicolumn{2}{|c|}{450}} & \multicolumn{2}{|l|}{90} & \multicolumn{2}{|l|}{145} & \multirow[t]{2}{*}{75} & 41 \\
\hline & & & & & & & & & \\
\hline$\gamma-\mathrm{CD}$ & $\mathbf{S}$ & $\mathbf{R}$ & 1 & 2 & 1 & 2 & 1 & 2 & 1 & 2 \\
\hline $\mathbf{K}^{\prime}(\mathrm{X})$ & 118 & 75 & 639 & 564 & 171 & 145 & 145 & 97 & 63 & 39 \\
\hline $\mathbf{K}^{\prime}(\mathbf{Y})$ & 118 & 76 & 639 & 559 & 173 & 142 & 160 & 107 & 65 & 41 \\
\hline$K^{\prime}(X Y)$ & 121 & 75 & 652 & 581 & 178 & 154 & 134 & 89 & 60 & 36 \\
\hline $\mathbf{K}^{\prime}(\mathrm{XYZ})$ & 117 & 81 & 628 & 554 & 167 & 135 & 170 & 122 & 74 & 49 \\
\hline & & & & & & & & & & \\
\hline $\mathrm{HP}-\alpha-\mathrm{CD}$ & $\mathbf{S}$ & $\mathbf{R}$ & & & 1 & 2 & 1 & 2 & 1 & 2 \\
\hline $\mathbf{K}^{\prime}(\mathrm{X})$ & 60 & 29 & & & 91 & 53 & 95 & 72 & 56 & 23 \\
\hline$K^{\prime}(Y)$ & 60 & 29 & & & 91 & 53 & 93 & 69 & 55 & 23 \\
\hline $\mathbf{K}^{\prime}(\mathbf{X Y})$ & 62 & 29 & & & 93 & 56 & 106 & 83 & 57 & 25 \\
\hline $\mathbf{K}^{\prime}(\mathrm{XYZ})$ & 56 & 25 & & & 86 & 57 & 79 & 49 & 51 & 21 \\
\hline & & & & & & & & & & \\
\hline $\mathrm{HP}-\beta-\mathrm{CD}$ & $\mathbf{S}$ & $\mathbf{R}$ & & & 1 & 2 & 1 & 2 & 1 & 2 \\
\hline$K^{\prime}(X)$ & 264 & 159 & & & 195 & 125 & 443 & 268 & 219 & 113 \\
\hline$K^{\prime}(Y)$ & 268 & 160 & & & 183 & 118 & 457 & 270 & 208 & 109 \\
\hline $\mathbf{K}^{\prime}(\mathrm{XY})$ & 263 & 160 & & & 204 & 135 & 439 & 266 & 234 & 128 \\
\hline $\mathbf{K}^{\prime}(\mathrm{XYZ})$ & 279 & 164 & & & 197 & 117 & 460 & 272 & 212 & 109 \\
\hline HP- $\gamma-C D$ & $\mathbf{S}$ & $\mathbf{R}$ & 1 & 2 & 1 & 2 & 1 & 2 & 1 & 2 \\
\hline $\mathbf{K}^{\prime}(\mathbf{X})$ & 91 & 52 & 607 & 476 & 109 & 90 & 122 & 71 & 34 & 14 \\
\hline $\mathbf{K}^{\prime}(\mathbf{Y})$ & 95 & 53 & 644 & 470 & 115 & 94 & 125 & 73 & 35 & 15 \\
\hline $\mathbf{K}^{\prime}(\mathrm{XY})$ & 93 & 51 & 598 & 473 & 103 & 84 & 124 & 72 & 34 & 14 \\
\hline $\mathrm{K}^{\prime}(\mathrm{XYZ})$ & 96 & 57 & 655 & 483 & 121 & 96 & 137 & 81 & 36 & 15 \\
\hline TM- $\beta-C D$ & $\mathbf{S}$ & $\mathbf{R}$ & 1 & 2 & 1 & 2 & 1 & 2 & 1 & 2 \\
\hline $\mathbf{K}^{\prime}(\mathbf{X})$ & 125 & 51 & 38 & 24 & 59 & 42 & 155 & 71 & 95 & 49 \\
\hline $\mathbf{K}^{\prime}(\mathbf{Y})$ & 128 & 51 & 40 & 24 & 60 & 42 & 158 & 70 & 94 & 48 \\
\hline $\mathbf{K}^{\prime}(\mathrm{XY})$ & 120 & 50 & 34 & 24 & 54 & 43 & 156 & 77 & 90 & 48 \\
\hline $\mathbf{K}^{\prime}(\mathrm{XYZ})$ & 135 & 55 & 51 & 17 & 65 & 38 & 163 & 66 & 92 & 44 \\
\hline
\end{tabular}


Table 6: Comparison between the theoretical optimal concentration of the cyclodextrin $\left[\mathrm{C}_{\mathrm{opt}}\right]_{\mathrm{cal}}$ calculated from (eq.12) and the experimental optimal concentration of the cyclodextrin determined experimentally $\left[\mathrm{C}_{\mathrm{opt}}\right]_{\exp }$ at $\mathrm{pH}=11.5$ for various binaphthols and cyclodextrins (concentration in $\mathrm{mM}$ ).

\begin{tabular}{|c|c|c|c|c|c|}
\hline$\alpha-C D$ & Binol & BN2 & BN3 & BN4 & BN5 \\
\hline$\left[\mathrm{C}_{\text {opt }}\right]_{\mathrm{cal}}$ & 56.2 & - & - & 25 & 26.3 \\
\hline$\left[\mathrm{C}_{\text {opt }}\right]_{\exp }$ & 20 & - & - & 20 & 20 \\
\hline$\beta-C D$ & Binol & BN2 & BN3 & BN4 & BN5 \\
\hline$\left[\mathrm{C}_{\mathrm{opt}}\right]_{\mathrm{cal}}$ & 3.9 & 1.4 & 6.7 & 5.2 & 12.6 \\
\hline$\left[\mathrm{C}_{\mathrm{opt}}\right]_{\exp }$ & 10 & 1.2 & 8 & 4 & 10 \\
\hline$\gamma-\mathrm{CD}$ & Binol & $\overline{\text { BN2 }}$ & BN3 & BN4 & BN5 \\
\hline$\left[\mathrm{C}_{\text {opt }}\right]_{\text {cal }}$ & 5 & 1.5 & 4.4 & 4.5 & 7.3 \\
\hline$\left[\mathrm{C}_{\text {opt }}\right]_{\exp }$ & 6 & 2 & 7.5 & 4 & 7 \\
\hline $\mathrm{HP}-\alpha-\mathrm{CD}$ & Binol & BN2 & BN3 & BN4 & BN5 \\
\hline$\left[\mathrm{C}_{\text {opt }}\right]_{\text {cal }}$ & 14.8 & - & 9.3 & 14.6 & 17.4 \\
\hline$\left[\mathrm{C}_{\text {opt }}\right]_{\exp }$ & 15 & - & 10 & 10 & 15 \\
\hline $\mathrm{HP}-\beta-\mathrm{CD}$ & Binol & BN2 & BN3 & BN4 & BN5 \\
\hline$\left[\mathrm{C}_{\text {opt }}\right]_{\text {cal }}$ & 4.2 & - & 5.2 & 2.8 & 5.2 \\
\hline$\left[\mathrm{C}_{\text {opt }}\right]_{\exp }$ & 4.4 & - & 10 & 3.3 & 6 \\
\hline $\mathrm{HP}-\gamma-\mathrm{CD}$ & Binol & BN2 & BN3 & BN4 & BN5 \\
\hline$\left[\mathrm{C}_{\mathrm{opt}}\right]_{\mathrm{cal}}$ & 9.8 & 1.6 & 7.5 & 7.3 & 10.8 \\
\hline$\left[\mathrm{C}_{\text {opt }}\right]_{\exp }$ & 8 & 2 & 7.5 & 7.5 & 8 \\
\hline TM- $\beta-C D$ & Binol & BN2 & BN3 & BN4 & BN5 \\
\hline$\left[\mathrm{C}_{\text {opt }}\right]_{\mathrm{cal}}$ & 9.9 & 30 & 13.6 & 8.3 & 9.7 \\
\hline$\left[\mathrm{C}_{\text {opt }}\right]_{\exp }$ & 10 & 25 & 15 & 7.5 & 10 \\
\hline
\end{tabular}




\section{Reviewer Suggestions}

Bezhan Chankvetadze

Sepaserve GmbH, Johann-Krane-Weg 42,

48149 Munster, Germany

Tel.: +49 251200 6047; fax: +49 2512006048 .

E-mail address:.jpba_bezhan@yahoo.com

Pierre Gareil

Laboratory of Electrochemistry and Analytical Chemistry, UMR CNRS 7575, ENSCP, 11 rue Pierre et Marie Curie, 75231 Paris Cedex 05, France

Tel.: +331554263 71; fax: +33144276750.

E-mail address: pierre-gareil@enscp.fr

Jean-Luc Veuthey

Laboratory of Analytical Pharmaceutical Chemistry, School of Pharmaceutical

Sciences, University of Geneva, University of Lausanne, boulevard d'Yvoy 20, 1211

Geneva 4, Switzerland

E-mail address: jean-luc.veuthey@pharm.unige.ch

Philippe Morin

Institut de Chimie Organique et Analytique (ICOA), CNRS FR 2708, UMR 6005,

Universite d'Orleans, BP 6759, Orleans 45067 Cedex 2, France

Tel.: +332384945 90; fax: +33238417281.

E-mail address: philippe.morin@univ-orleans.fr 